\title{
THE EFFECT OF CRYSTALLIZING ADMIXTURE ON THE PROPERTIES AND SHRINKAGE OF CONCRETE
}

\author{
"DŽIGITA NAGROCKIENĖ, INA PUNDIENĖ, AUDRIUS ČEPULIS, EDVINAS POCIUS
}

Vilnius Gediminas Technical University, Sauletekio av. 11, Vilnius, LT-10223, Lithuania

\#E-mail: dzigita.nagrockiene@vilniustech.lt

Submitted May 31, 2021; accepted July 23, 2021

\begin{abstract}
Keywords: Crystallizing admixture, Concrete, Shrinkage, Compressive strength, Porosity
This study investigates the effect of the amount (from $0.6 \%$ to $1.4 \%$ ) of crystallizing admixture (CA) on the shrinkage, density, porosity and mechanical properties of concrete specimens. A higher content of CA increased the total porosity of concrete from $10.6 \%$ to $11.15 \%$. In contrast to the specimens containing $0.8-1.0 \%$ of CA, the lowest amount of closed pores and highest total porosity was observed in the specimens containing 1.2-1.4\% of the CA. Compared to the control specimen, concrete specimens containing $1.4 \%$ of CA showed a $5.4 \%$ decrease in flexural strength and a $13.6 \%$ decrease in compressive strength after 28 days of curing. The specimens containing $0.9-1.0 \%$ of CA demonstrated the lowest shrinkage in the period of 190 days. The shrinkage of these specimens reduced $4.8-4.9 \%$ compared to the control specimen. Higher content of CA had an opposite effect on the shrinkage, a short-term expansion of specimens was observed after 28-56 days. Taking into account all the properties of the concrete specimen, the optimum amount of $C A$, which could prevent cracks in the structures is $1.0 \%$ of the cement mass.
\end{abstract}

\section{INTRODUCTION}

The modern concrete currently produced has better properties due to the widespread use of chemical admixtures, thus reducing the consumption of traditional raw materials and reducing the impact on the environment. The durability of concrete must be increased to meet the requirements of modern constructions. Drying shrinkage is an important issue in modern concrete products as it causes concrete cracking. Shrinkage cracks is a serious problem, especially in structures with large spans, big volumes, high constraints, operated in aggressive environments. Researchers claim that shrinkage is responsible for $80 \%$ of cracks in concrete structures [1].

Cracks considerably reduce impermeability of concrete and resistance to chemical agents [2]. Materials that get inside the concrete structure through the cracks can accelerate the deterioration of concrete and corrosion of rebar [3]. Cracks can significantly reduce the durability of concrete structures, especially in aggressive environment. There are four types of concrete shrinkage: plastic shrinkage, self-shrinkage, carbonation shrinkage, and drying shrinkage. Plastic shrinkage occurs due to the release of free water from concrete during the first hours in the formwork. Self-shrinkage is caused by the loss of water through concrete pores during cement hydration. Carbonation shrinkage is caused by the chemical reaction with carbon dioxide, which enters the concrete mix from the ambient air. This type of shrinkage usually occurs on the bottom of concrete [4].
Drying shrinkage is described as the alteration of concrete volume due to the loss of moisture in hardened concrete. Moister moves through capillaries of concrete. The capillary force attempts to remove excess moisture in order to balance the amount of moister with the ambient environment. The fastest loss of moisture occurs in narrow structures and concrete products with big surface area. The studies showed that $40 \%$ of the total concrete shrinkage deformations occur after one month and $90 \%$ of the total deformations become apparent after one year. The size of shrinkage deformation depends on the following factors: concrete composition, shape of concrete product, concrete curing and concrete product operation conditions. The deformations may vary from $-3 \times 10^{-4}$ to $-6 \times 10^{-4}$, mm depending on the circumstances mentioned above [5].

Researchers tested the loss of water in concrete related to the drying shrinkage. According to the findings, the change in concrete volume is equal to the volume of the water lost. In the initial drying stage of concrete the free water is removed; later, the absorbed water is removed by hydrostatic force in small capillaries during the further drying [6].

Factors that affect the drying shrinkage of the concrete were investigated in the research [7]. These factors are the aggregates used (gravel, rubble, sand), water and cement ratio $(\mathrm{w} / \mathrm{c})$, relative humidity and the size of concrete product. According to the results of the study, coarser aggregates have a lower effect on shrinkage than finer aggregates. Aggregates with a higher modulus of 
elasticity and rough surface create better resistance to shrinkage. High shrinkage is directly related to a high water/cement ratio. High $\mathrm{w} / \mathrm{c}$ also reduces concrete strength and stiffness. Dimensions of concrete products have a direct effect on shrinkage, i.e. the shrinkage effect is much lower in concrete products of big dimensions.

Various fibres are effective to reduce plastic shrinkage in concrete curing phase. There are many studies confirming the effective use of glass fibre, polypropylene fibre, plastic fibre or composite fibres to reduce the shrinkage of concrete. The effectiveness of the commonly used wire mesh should not be overlooked either [8-13].

The effectiveness of polypropylene fibre was studied in the research [14]. Specimens with different fibre content were tested. According to concrete shrinkage test results, shrinkage during the first 24 hours can be reduced from $5 \%$ to $78 \%$ and from $20 \%$ to $39 \%$ during 77 days depending on the amount of fibre added.

Tests with flax fibre (fibre particle length of $10-38 \mathrm{~mm}$ ) were conducted to investigate the shrinkage reduction effect. The results showed that during the first 24 hours the shrinkage of flax modified concrete reduced $95 \%$ compared to the control specimen without fibres [15].

The effect of different type fibres on the shrinkage of concrete was also investigated. The study was not typical, as different combinations of fibres - steel, polypropylene, polyester, and glass - sourced from local producers were used. Researchers found that a combination of fibres is more effective to reduce the shrinkage of concrete. Test results showed that the shrinkage of concrete specimens modified with polypropylene and polyester fibres was 50 - $90 \%$ lower compared to unmodified concrete specimens. The combination of steel and polyester fibres was found to be the most effective as it reduced shrinkage cracks $99 \%$. The combination of glass and steel fibres, on the other hand, was found to be the most ineffective, most probably because of the inability of inflexible glass fibres to reduce the early shrinkage of concrete [16].

A study was conducted to investigate the effect of mineral admixtures on the cracking and shrinkage of concrete. Fly ash and limestone powder were used as mineral admixtures. Concrete cracking was found to be related not only with the shrinkage value, but also in the shrinkage speed and strains. Mineral admixtures were found to reduce the potential for cracking, the overall shrinkage rate and the potential for cracking were found to be higher in mixtures with a lower water cement ratio [17].

Researchers investigated the effect of temperature on concrete shrinkage. Five mixes with different fractions of fine aggregates were selected. Researchers found that shrinkage was related to temperature. No cracks developed at the recommended cooling temperature of $2.5^{\circ} \mathrm{C}$. The cooling temperature of $8{ }^{\circ} \mathrm{C}$ and above created a big difference of temperatures at the surface and inside the specimen and caused the development of cracks [18].

The development of shrinkage related defects can be reduced by reducing the degree of restraint of these deformations in a structure (e.g. the amount of rebar). Another way is to reduce the distance between structural joints in the design stage. The internal moisture demand can be reduced by replacing part of sand with water saturated light aggregates and using additional water to hydrate the cement particles.

Special admixtures can also be used to reduce concrete shrinkage. The positive effect of admixtures in preventing self-shrinkage of concrete is confirmed by research [19].

The influence of expanding agents, shrinkage inhibitors and hydrophobic admixtures on the white Portland cement based self-compacting concrete properties was investigated in research [20]. Researchers concluded that the lowest shrinkage and the most effective result was obtained when expansive agents and shrinkage inhibitors were used simultaneously.

Other researchers also studied the effect of expansive agents and shrinkage inhibitors on concrete shrinkage. The obtained results revealed that admixtures can significantly reduce or completely prevent the self-shrinkage of concrete. The synergistic effect of expansive agents and shrinkage inhibitors was also observed. Shrinkage inhibitor slows down the bonding of the concrete mix and thus increases the efficiency of expansive admixture [21].

The tests showed that shrinkage inhibitors may be used in those cases, where concrete shrinkage can cause durability problems and is also not desirable for economic or technical reasons. Shrinkage inhibitors most often contain ethylene glycol derivatives. These admixtures reduce shrinkage by blocking the pores of concrete and preventing water evaporation. Unfortunately, these admixtures can also reduce concrete strength. According to the test results, the highest loss if strength may reach 12 - $15 \%$ during 28 days [22].

Researchers also investigated the effect of shrinkage inhibitors on the properties of self-compacting concrete. Shrinkage inhibitors were found to have no effect on self-compaction. Shrinkage was found to reduce with a higher content of chemical admixture in concrete mix, however the values of concrete strength were lower [23].

Some experiments were conducted with shrinkage inhibitors based on different types of glycol. Researchers found that long-term shrinkage reduced 0 - $56 \%$ compared to unmodified specimens. Similar tests were done with wax-based shrinkage inhibitors, which caused only $13 \%$ reduction of shrinkage [24].

In summary of research papers analysed, there is a unanimous recognition of the damage caused by concrete shrinkage. There is a need for solutions to prevent shrinkage cracks in concrete and increase the durability of concrete structures. However, different shrinkage 
prevention materials were used in the aforementioned studies and there is no generally established view as to which material is the best to tackle this problem. Besides, fibre is not always possible to use as special conditions and mixers are needed to meet the mixing requirements. Therefore, producers of concrete admixtures and additions develop and propose a great variety of shrinkage reducing, crack self-healing, active waterproofing agents to be used in concrete manufacturing. A crystallising admixture (CA) in the form of powder is one of the products offered. CA can be used both to increase the durability of concrete and to prevent shrinkage cracks, but the effect of this admixture on the physical and mechanical properties and shrinkage of concrete has not been well investigated yet. A research into this admixture would help concrete manufacturers to forecast the potential changes of concrete influenced by different amount of the CA in the period of 190 days.

\section{EXPERIMENTAL}

The binding material used for the tests was cement CEM II/A-LL 42.5 with the properties provided in Table 1. The concrete specimens tested contained CA (density $980 \mathrm{~kg} \cdot \mathrm{m}^{-3}$ ), sand of fraction $0 / 4$, granite rubble of fraction $2 / 5$. The properties of the aggregates are presented in Table 2.

Table 1. Characteristics of Portland cement.

\begin{tabular}{lccc}
\hline Marking & $\begin{array}{c}\text { Bulk } \\
\text { density } \\
\left(\mathrm{kg} \cdot \mathrm{m}^{-3}\right)\end{array}$ & $\begin{array}{c}\text { Particle } \\
\text { density } \\
\left(\mathrm{kg} \cdot \mathrm{m}^{-3}\right)\end{array}$ & $\begin{array}{c}\text { Specific } \\
\text { surface area } \\
\left(\mathrm{cm}^{2} \cdot \mathrm{g}^{-1}\right)\end{array}$ \\
\hline CEM II/A-LL 42,5 N & 1100 & 3100 & 4100 \\
\hline
\end{tabular}

Table 2. Aggregate properties.

\begin{tabular}{lcc}
\hline Properties & Sand & Granite rubble \\
\hline Particle size distribution & $0 / 4$ & $2 / 5$ \\
\hline Particle density $\left(\mathrm{kg} \cdot \mathrm{m}^{-3}\right)$ & 2620 & 2670 \\
\hline Bulk density $\left(\mathrm{kg} \cdot \mathrm{m}^{-3}\right)$ & 1650 & 1460 \\
\hline $\begin{array}{l}\text { Water absorption }(\mathrm{wt} . \%) \\
\text { (after } 24 \text { h of soaking) }\end{array}$ & $\leq 1,0$ & $\leq 2,0$ \\
\hline Water - soluble chlorides $(\%)$ & $\leq 0,01$ & $\leq 0,01$ \\
\hline
\end{tabular}

Concrete specimens were prepared according to LST EN 12390-2 [25]. Compositions of concrete mix are presented in Table 3. Specimens were formed by increasing the amount of CA in the mixture. The amount of CA was calculated as a percentage of the cement content. The mixtures were mechanically mixed in laboratory conditions and specimens with dimensions of $40 \times 40 \times 160 \mathrm{~mm}$ were formed in steel moulds lined with oil. The mixture in the mould was compacted on the vibration table. After 24 hours, the specimens were removed from the moulds and kept in a water bath of $20{ }^{\circ} \mathrm{C}$ until testing. A constant water/cement ratio of 0.52 was maintained in all compositions.

Phase analysis of crystallizing admixture was done by X-ray diffraction meter SmartLab (Rigaku) with a rotating $\mathrm{Cu}$ anode X-ray generator tube of $9 \mathrm{~kW}$. X-ray diffraction patterns were recorded in the angular range $5-75^{\circ}(2 \theta)$, detector step $0.02^{\circ}$, detector movement speed $1^{\circ}$ per minute. Database of crystal structures PDF$4+$ (2016) was used for the analysis. The microstructure of CA was inspected using SEM Helios NanoLab 650. The entrained air content was measured on concrete mixture by EN 12350-7 using pressure gauge method and equipment.

Density of hardened cement paste was measured according to LST EN 12390-7:2019 [26], compressive strength according to LST EN 12390-3:2019 [27], flexural strength according to LST EN 12390-5:2019 [28], and shrinkage according to LST EN 12390-16:2019 [29] requirements.

\section{RESULTS AND DISCUSSION}

The mineral structure of the CA was tested by means of X-ray diffraction analysis. The results of X-ray diffraction analysis are presented in Figure 1. X-ray diffraction image reveals that the prevailing mineral $(48.5 \%)$ of $\mathrm{CA}$ is sodium carbonate $\left(\mathrm{Na}_{2} \mathrm{CO}_{3}\right)$. Authors have noted [30-31] that $\mathrm{Na}_{2} \mathrm{CO}_{3}$ can accelerate hydration of cement and mostly accelerates $\mathrm{C}_{3} \mathrm{~S}$ hydration because the layer of hydrates around $\mathrm{C}_{3} \mathrm{~S}$ particles in carbonate solution starts depleting after some time due to the surplus of $\mathrm{CO}_{3}{ }^{2-}$ ions. This leads to a significant increase in the speed of $\mathrm{Ca}^{2+}$ and $\mathrm{OH}^{-}$diffusion and thus the hydration accelerates. Tricalcium silicate $\left(\mathrm{Ca}_{3} \mathrm{SiO}_{4}\right)$

Table 3. Concrete compositions design for $1 \mathrm{~m}^{3}$.

\begin{tabular}{|c|c|c|c|c|c|c|c|c|c|c|}
\hline Batches & I & II & III & IV & V & VI & VII & VII & VIII & IX \\
\hline Cement (kg) & 385 & 385 & 385 & 385 & 385 & 385 & 385 & 385 & 385 & 385 \\
\hline Sand 0/4 (kg) & 656 & 656 & 656 & 656 & 656 & 656 & 656 & 656 & 656 & 656 \\
\hline Granite rubble $2 / 5(\mathrm{~kg})$ & 1150 & 1150 & 1150 & 1150 & 1150 & 1150 & 1150 & 1150 & 1150 & 1150 \\
\hline Water $\left(\mathrm{kg} \cdot \mathrm{m}^{-3}\right)$ & 200 & 200 & 200 & 200 & 200 & 200 & 200 & 200 & 200 & 200 \\
\hline $\mathrm{CA}(\%)$ & 0 & 0.6 & 0.7 & 0.8 & 0.9 & 1.0 & 1.1 & 1.2 & 1.3 & 1.4 \\
\hline $\mathrm{CA}(\mathrm{kg})$ & 0.00 & 2.31 & 2.70 & 3.08 & 3.47 & 3.85 & 4.24 & 4.62 & 5.01 & 5.39 \\
\hline $\mathrm{W} / \mathrm{C}$ & 0.52 & 0.52 & 0.52 & 0.52 & 0.52 & 0.52 & 0.52 & 0.52 & 0.52 & 0.52 \\
\hline
\end{tabular}


$\mathrm{T}$ is the second $(34 \%)$ and Portlandite $\left(\mathrm{Ca}(\mathrm{OH})_{2}\right) \mathrm{P}$ is the third $(7 \%)$ prevailing mineral in the CA. The CA also contains smaller amounts of the following minerals: $5 \%$ of quartz $\left(\mathrm{SiO}_{2}\right) \mathrm{K}, 2.6 \%$ of aluminium silicate $\left(\mathrm{Al}_{2} \mathrm{O} \mathrm{SiO}_{4}\right) \mathrm{A}, 1.53 \%$ of calcium aluminium hydro silicate $\left(\mathrm{CaAl}_{2}(\mathrm{OH})_{8}\left(\mathrm{H}_{2} \mathrm{O}\right)_{3.84}\right) \mathrm{C}$, and $0.7 \%$ of calcium silicate $\left(\mathrm{CaSiO}_{3}\right) \mathrm{O}$. According to a literature source [32], $\mathrm{C}_{3} \mathrm{~S}$ is added to the $\mathrm{CA}$ in order to accelerate hydration and to increase the early strength of concrete. According to the findings in the kinetics of tricalcium silicate hydration, $\mathrm{Na}_{2} \mathrm{CO}_{3}$ accelerates early strength development [33].

The microstructure of CA is presented in SEM images in Figure 2. The image magnified 1000 times (Figure $2 \mathrm{a}$ ) shows that smaller size $5-10 \mu \mathrm{m}$ particles prevail. The image magnified 6500 times (Figure $2 b$ ) shows that CA particles are made of irregular shape crystals and angular crystals distributed in different directions.

The effect of CA dosage on entrained air content in the control concrete mixture and mixtures modified with $0.6 \%, 1.0 \%$ and $1.4 \%$ of $\mathrm{CA}$ is presented in Figure 3 . With the increase of CA amount to $0.6 \%$ and $1.0 \%$, the air content in the concrete mixture increase from $5.9 \%$

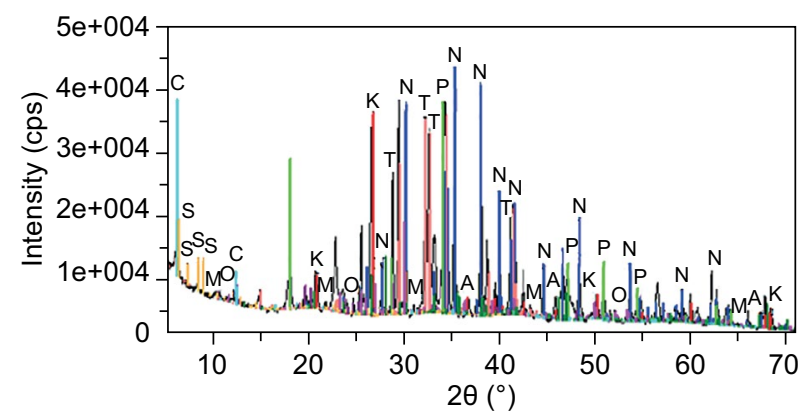

Figure 1. X-ray image of CA: $\mathrm{N}$ - sodium carbonate $\left(\mathrm{Na}_{2} \mathrm{CO}_{3}\right)$, $\mathrm{T}$ - tricalcium silicate $\left(\mathrm{Ca}_{3} \mathrm{SiO}_{4} \mathrm{O}\right), \mathrm{K}$ - quartz $\left(\mathrm{SiO}_{2}\right), \mathrm{A}$ - aluminium silicate $\left(\mathrm{Al}_{2} \mathrm{OSiO}_{4}\right), \mathrm{O}$ - calcium silicate $\left(\mathrm{CaSiO}_{3}\right), \mathrm{P}-$ - portlandite $\left(\mathrm{Ca}(\mathrm{OH})_{2}\right), \mathrm{C}$ - calcium aluminium hydro silicate $\left(\mathrm{CaAl}_{2}(\mathrm{OH})_{8}\left(\mathrm{H}_{2} \mathrm{O}\right) 3.84\right), \mathrm{M}$ - meta-aluminate $\mathrm{Al}_{2} \mathrm{SO}_{4}$ $(\mathrm{OH})_{4} \cdot 5 \mathrm{H}_{2} \mathrm{O}, \mathrm{S}-\mathrm{Si}_{73} \mathrm{O}_{144}(\mathrm{OH})_{4}$.

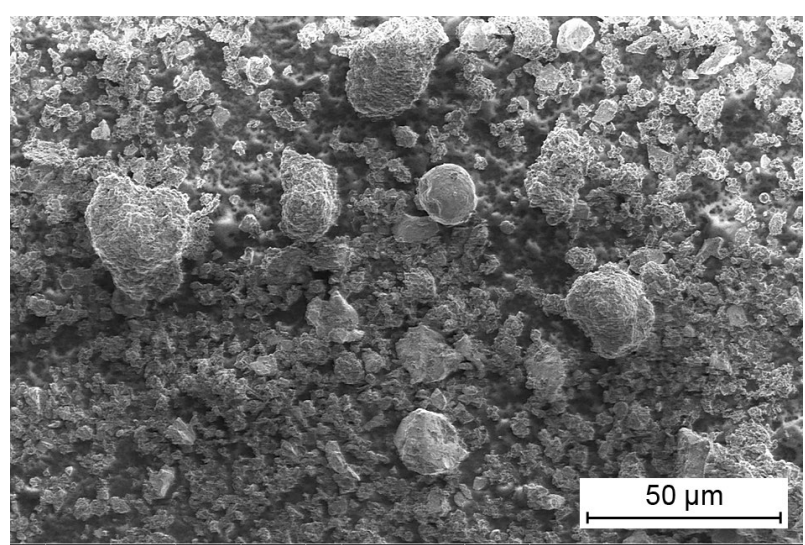

a) $\times 1000$ (in the control specimen) to $6.4 \%$. The biggest increase of the amount of entrained air to $7.2 \%$ was observed when the CA dosage was increased to $1.4 \%$.

Density tests revealed (Figure 4) that the density of concrete specimen reduces when the amount of CA is increased up to $1.4 \%$. The density of CA modified concrete reduces by $1.4 \%$ in average. The lowest CA amount $(0.6 \%)$ reduces the density by $0.8 \%$, and the highest CA amount $(1.4 \%)$ reduces the density by $1.7 \%$.

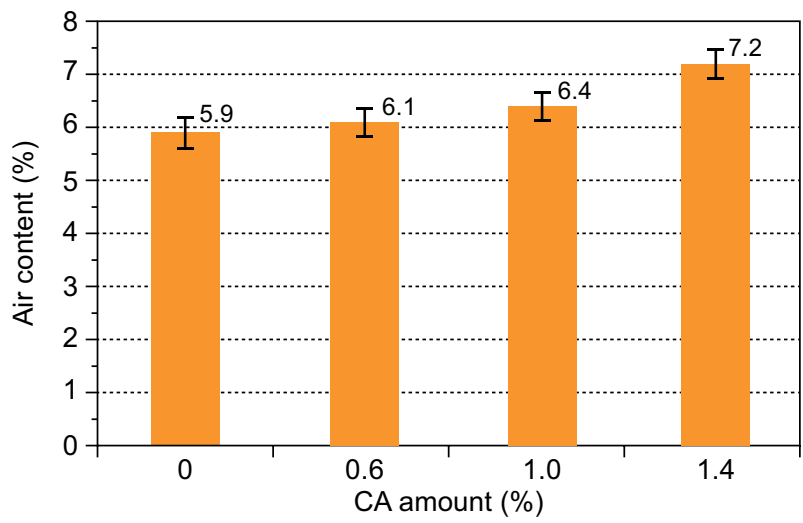

Figure 3. Relationship between entrained air content and CA amount in the concrete composition mixture.

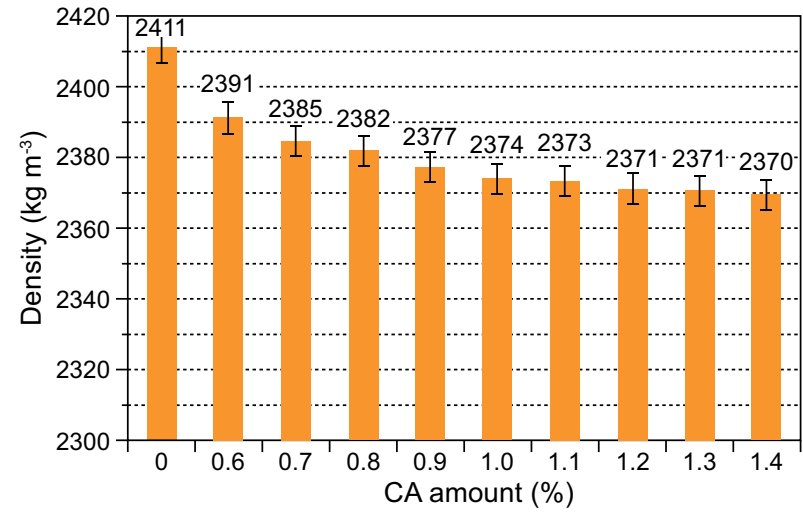

Figure 4. Relationship between density and CA amount in the concrete composition specimens.

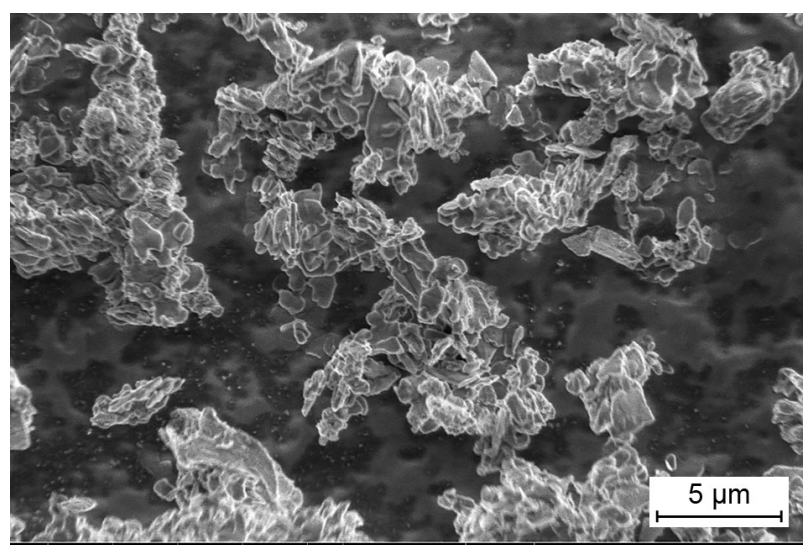

b) $\times 6500$

Figure 2. The microstructure of the CA: a) $\times 1000$ magnification; b) $\times 6500$ magnification. 
Apparently, the CA, that has a lower bulk density than cement, promotes the development of a porous structure in concrete specimens. This hypothesis is also supported by entrained air tests. Similar trends were observed in hardened cement paste, the composition of which contained $2 \%$ and $4 \%$ of $\mathrm{Na}_{2} \mathrm{CO}_{3}$ [30].

Open, closed, and total porosities of CA modified concrete specimens were tested. The obtained results are presented in the Table 5 . The lowest open porosity value of $7.82 \%$ was obtained in control specimens. These specimens also had the highest density. They contained much less free water, which affects the development of open pores. The highest open porosity value $(8.71 \%)$ was obtained in the specimens modified with the highest amount $(1.4 \%)$ of the CA. Faster hydration of $\mathrm{C}_{3} \mathrm{~S}$ in the presence of $\mathrm{Na}_{2} \mathrm{CO}_{3}$ has a significant effect on the development of the pore structure [30]. Due to the excess of $\mathrm{CO}_{3}{ }^{2-}$ ions, the amorphous $\mathrm{CaCO}_{3}$ particles are quickly transformed (in a few minutes) into a crystalline phase which, appears along with C-S-H gel in the system of hydrated $\mathrm{C}_{3} \mathrm{~S}$ - carbonates.

The test results presented in Figure 5 show that the highest closed porosity values of $2.83,2.88$, and $2.86 \%$ were obtained in the specimens modified with $0.8,1.0$, and $1.1 \% \mathrm{CA}$. The closed porosity in modified specimens was 1.8-3.6\% higher than in control specimens. The specimens modified with $1.4 \% \mathrm{CA}$ had the lowest closed porosity value $(2.48 \%)$. The control specimens had the total porosity of $10.60 \%$. With $1.4 \%$ of CA added the total porosity increased up to $11.15 \%$. The open porosity of concrete specimens modified with $0.8,1.0$ and $1.1 \%$ CA increased from 7.89 to $8.06 \%$, while the specimen modified with $1.4 \%$ of CA had the open porosity of $8.71 \%$. We may see that with higher than $1.1 \% \mathrm{CA}$ in the composition the closed porosity decreases while the open and total porosity increases. The ratio of open to closed porosity in the specimens containing $0.0-1.0 \%$ of CA varies within $2.81-2.76$, but in the specimens containing 1.1-1.4\% of CA varies within $2.91-3.51$. Changes in the ratio of open to closed pores affect the properties of the concrete. According to

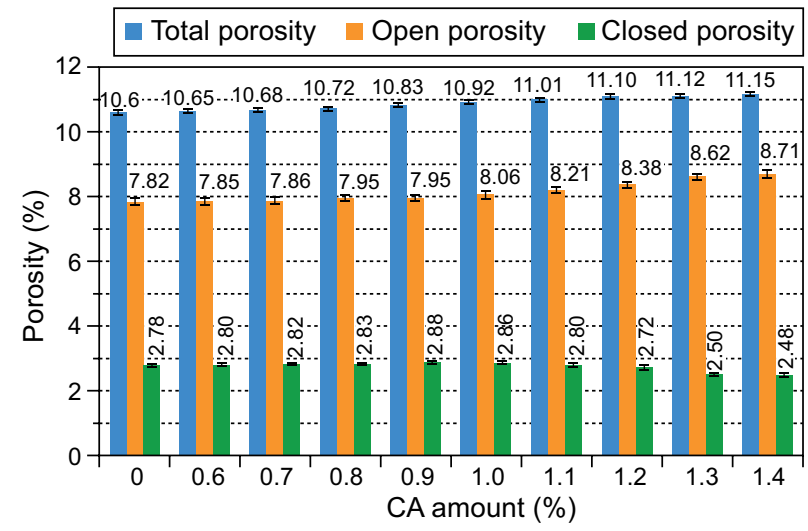

Figure 5. Relationship between porosity and CA amount in the concrete composition specimens. research publications, carbonate salts can increase the porosity of concrete specimens, however higher amounts of these salts can increase the amount of damage-causing pores [34]. Another test, reporting the results of addition of sodium aluminate admixture to concrete showed, that the addition of sodium aluminate at $2 \%, 4 \%, 6 \%$, and $8 \%$ by weight percent of cement increase the porosity of concrete specimens. From the amounts of sodium aluminate investigated $(2 \%, 4 \%, 6 \%$, and $8 \%)$ only the addition of 2 - $4 \%$ was found to improve the properties of concrete as the specimens modified with this amount were found to have a higher volume of small capillary pores $(5-30 \mathrm{~nm})$ and a lower volume of larger pores $(>30 \mathrm{~nm})$. Higher amounts of sodium aluminate did not improve the properties of concrete [35].

The ultrasonic pulse velocity (UPV) tests (Figure 6) showed that the UPV in concrete specimens decreases when the amount of CA is increased up to $1.4 \%$. Compared to the control specimen, the UPV in specimens modified with $0.6 \%$ and $0.7 \%$ of CA increased insignificantly, just by $0.2 \%$ and $0.04 \%$ respectively. The values of UPV in concrete tend to decrease with higher amount of CA in the concrete composition. The UPV in the specimen containing the highest amount of the CA reduced by $1.3 \%$ compared to the control specimen. $\mathrm{CA}$ tests confirm the findings of density and porosity tests.

Figure 7 illustrates the flexural strength of the specimens after 7 and 28 days of curing. The analysis of flexural strength test results leads to the conclusion that a higher amount of CA reduces the flexural strength at 7 and 28 days. The flexural strength of modified specimens decreases $5.25 \%$ in average compared to the control specimen. It can be influenced both by the higher porosity of CA modified specimens and by morphological changes in hydration products. According to the literature source [35], during the hydration process the sodium ions changed the morphology of calcium sulfoaluminate (AFm), by transforming the acicular to tabular AFm. Therefore, the decrease in the flexural strength must be considered in the design of concrete structures modified by CA.

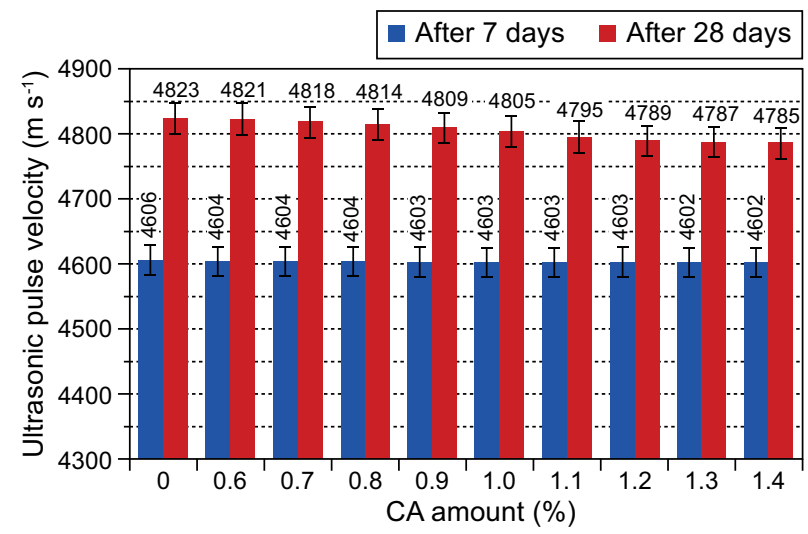

Figure 6. Relationship between UPV and CA amount in the concrete composition specimens. 
Nagrockienè D., Pundienè I., Čepulis A., Pocius E.

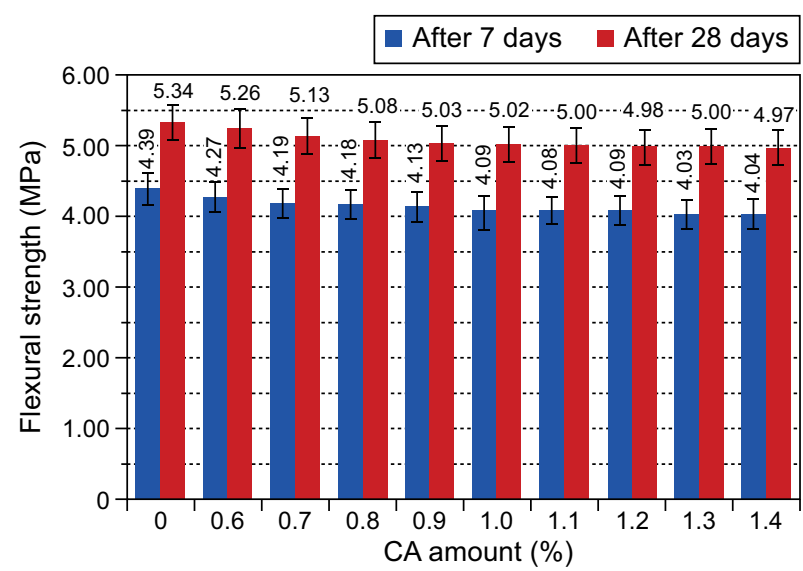

Figure 7. Relationship between the flexural strength at 7 and 28 days and $\mathrm{CA}$ amount in the concrete composition specimens.

Figure 8 illustrates the compressive strength of the specimens after 7 and 28 days of curing. At 7 and 28 days, the compressive strength of concrete specimens reduces with increasing amount of CA. The average compressive strength of control specimens was $40.3 \mathrm{MPa}$ at 7 days while the compressive strength of the specimens modified with $1.4 \%$ of CA reduced to 36.0 MPa. The increase in the content of CA caused a $10.7 \%$ drop of compressive strength. At 28 days, the compressive strength of control specimens increased to $54.6 \mathrm{MPa}$, whereas the compressive strength of the specimens modified with $1.4 \%$ of CA increased only to $47.2 \mathrm{MPa}$. The compressive strength of the modified specimens was $13.6 \%$ lower than the strength of control specimens.

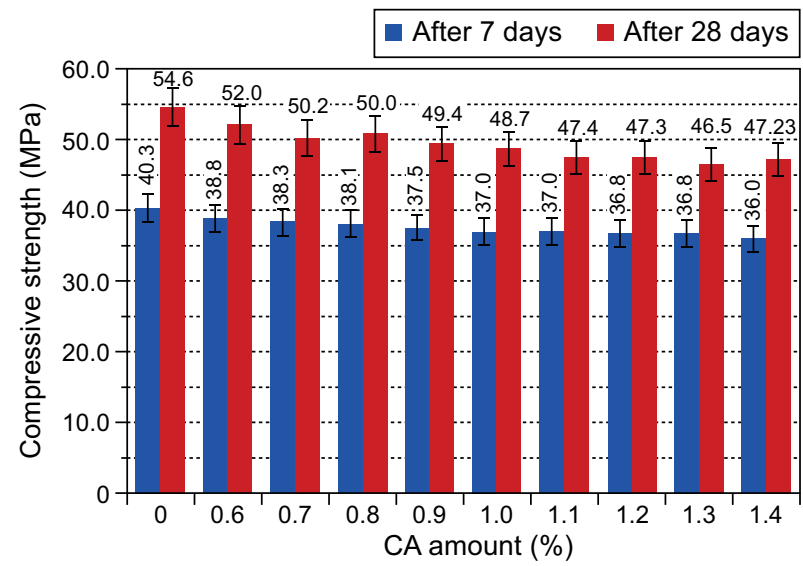

Figure 8. Relationship between the compressive strength at 7 and 28 days and CA amount in the concrete composition specimens.

Many researchers noted [31, 36-38] that carbonate salts, such as $\mathrm{Na}_{2} \mathrm{CO}_{3}$ and $\mathrm{NaHCO}_{3}$, can reduce the compressive or tensile strengths of concrete irrespective of the admixture content or hardening time. A significant drop in compressive strength was observed after 28 days of hardening [31]. The compressive strength of concrete specimens is closely related to porosity, which in turn depends on the volume of hydrates formed. $\mathrm{Na}_{2} \mathrm{CO}_{3}$ promotes the formation of the bigger volume of hydrates, especially ettringite. With a higher content of $\mathrm{Na}_{2} \mathrm{CO}_{3}$ in the compositions, the compressive strength of concrete decreases [31].

Shrinkage tests revealed that shrinkage of specimens reduces with a higher content of CA (Figure 9). The highest shrinkage reduction was observed in the specimens containing $1.0 \%$ of CA. The shrinkage in specimens containing $1.2 \%$ or a higher content of CA was higher than the shrinkage in control specimens.

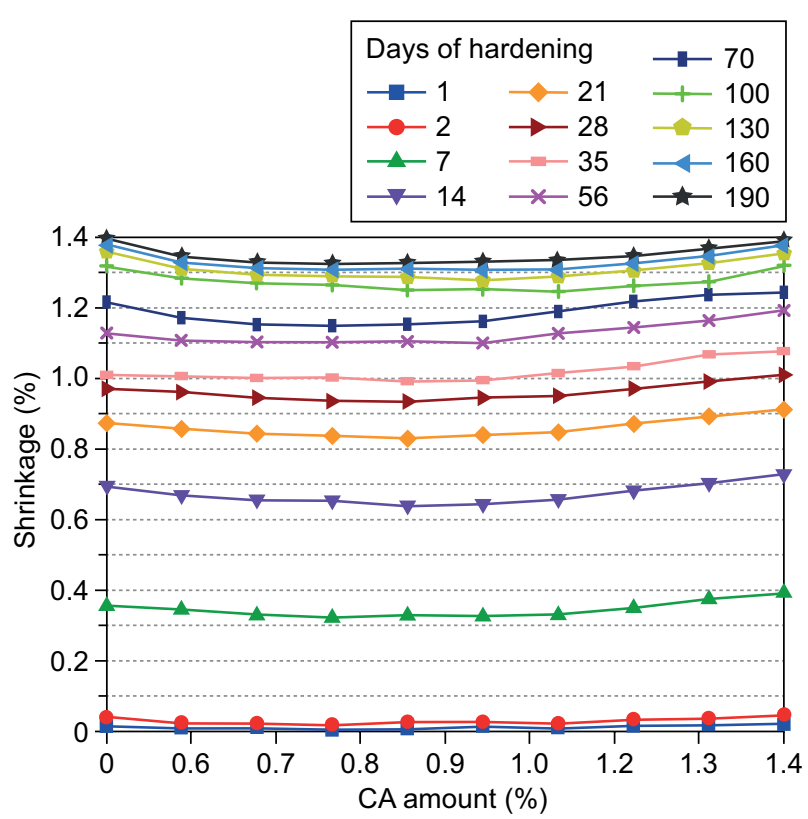

Figure 9. Relationship between shrinkage and CA amount in the concrete composition specimens.

Comparative calculations of shrinkage reduction, calculated in (\%) compared to control concrete specimens, were done (Figure 10) in order to better evaluate the effect of the CA amount on the specimen shrinkage after 28 - 190 days of hardening. It can be observed that shrinkage increases with longer hardening time from 28 to 190 days, but the most significant changes in the shrinkage depending on the amount of CA added are observed after 28 and 56 days. Compared with the shrinkage of the control specimen that was considered to be $100 \%$, the shrinkage of the specimens modified with $0.6-0.9 \%$ CA decreased to $98.93-96.15 \%$, the shrinkage of the specimens modified with $1.0-1.1 \%$ CA decreased to $97.23-97.87 \%$, whereas the specimens modified with $1.2-1.4 \%$ CA showed an opposite trend, i.e. they expanded to $104.06 \%$ after 28 days of hardening. The same trend was observed after 56 days and the expansion of mentioned specimens reaches $105.7 \%$. The observed shrinkage changes in the specimens with a higher CA amount may be related to the formation of a higher volume hydrates, especially ettringite and 
subsequent morphological changes in these hydrates [31, 35]. Shrinkage was observed in all specimens during the longer hardening time up to 190 days, but the specimens containing $0.8-1.0 \%$ of CA had the lowest shrinkage of $94.8-95.39 \%$, whereas the shrinkage of the specimens containing $1.1-1.4 \%$ CA was $95.7-99.56 \%$. It can be concluded that $\mathrm{CA}$ amount above $1.1 \%$ does not improve the shrinkage properties of the concrete specimens, whereas $1.4 \%$ of CA has a negative effect on concrete shrinkage.

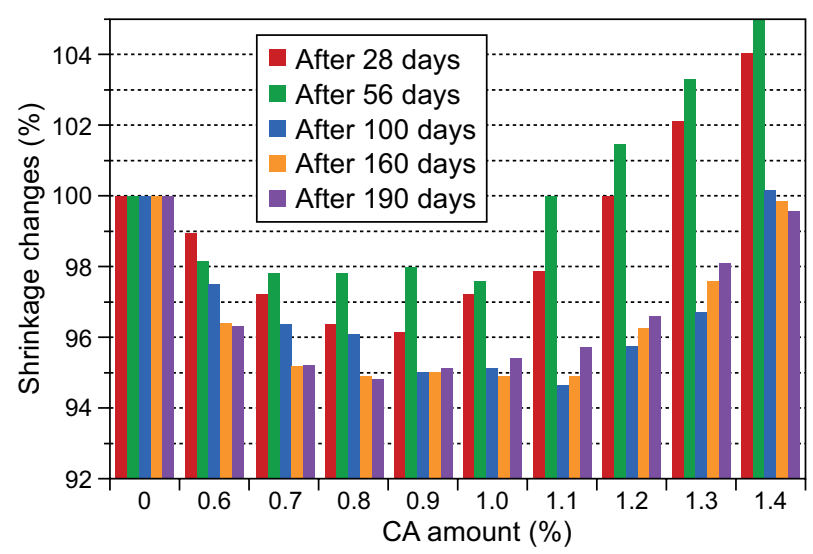

Figure 10. Relationship between the shrinkage changes (\%) and the curing time along with $\mathrm{CA}$ amount in the concrete composition specimens.

The analysis of the relationship between concrete shrinkage and time showed that the early shrinkage changes much faster than the late/long-term shrinkage. These observation results can be related to the changes in the volume of hydration products, especially ettringite $[31,35]$ and an early loss of free water. A slower growth in shrinkage observed after 100 - 190 days is related to later stages of cement hydration.

\section{CONCLUSIONS}

The tests results showed that porosity of concrete specimens increases, but density decreases with a higher amount of $\mathrm{CA}$ in the concrete composition. The lowest amount $(0.6 \%)$ of $\mathrm{CA}$ reduces the density of concrete by $0.8 \%$, and the highest amount $(1.4 \%)$ reduces the density by $1.7 \%$. The total and open porosity increases from $10.6 \%$ to $11.15 \%$ and from 7.82 to $8.71 \%$ with a higher amount of CA. However, the specimens containing $0.8 \%, 0.9 \%$ and $1.0 \%$ of CA had a lower open porosity $(7.89 \%, 7.95 \%$ and $8.06 \%)$ and higher closed porosity $(2.83 \%, 2.88 \%$ and $2.86 \%)$ than specimens modified with 1.2-1.4\% of the CA. The lowest amount of closed pores and highest total porosity was observed in the specimens modified with $1.2-1.4 \%$ of the CA. The ratio of open to closed porosity in the specimens containing $0.0-1.0 \%$ of CA varies within $2.81-2.76$, but in the specimens containing $1.1-1.4 \%$ of CA varies within $2.91-3.51$. Such changes in the ratio of open to closed porosity in the specimens affect the properties of the concrete.

Ultrasonic pulse velocity tests confirm the findings of density and porosity tests. The values of ultrasonic pulse velocity in concrete tend to decrease with a higher content of CA in the concrete composition. The ultrasonic pulse velocity in the specimen containing the highest amount of the CA reduced $0.8 \%$ compared to the control specimen.

The flexural and compressive strengths were found to decrease with higher contents of CA. After 28 days of hardening the flexural strength of modified specimens decreased $5.4 \%$ in average compared to the control specimen. After 28 days of hardening the compressive strength of specimens containing $1.4 \%$ of the CA reduced $13.6 \%$ compared to the control specimen.

The specimens containing $0.9-1.0 \%$ of CA demonstrated the lowest shrinkage in the period of 190 days. The shrinkage of these specimens reduced $4.8-4.9 \%$ compared to the control specimen. $1.2 \%$ and higher content of CA had the opposite effect, i.e., the shrinkage did not decrease or a short-term expansion of specimens was observed after 28 - 56 days.

According to the test results, the recommended optimal amount of CA is $0.9-1 \%$ by weight of cement. The best results in terms of shrinkage were observed in specimens modified with $0.8-1.1 \%$ of the CA.

The findings of this research work are relevant in situations where the appearance of cracks in concrete structures is a serious issue. Basing on the test results it can be stated that $\mathrm{CA}$ have a positive effect, i.e. reduce the shrinkage of concrete and thus prevent the development of cracks in concrete structures.

\section{REFERENCES}

1. Wang T.M. (2007). Control of cracking in engineering structure. China Architecture \& Building Press (Beijing).

2. Wang K., Jansen D., Shah S.P. Karr A. (1997): Permeability study of cracked concrete. Cement and Concrete Research, 27(3), 381-393. Doi: 10.1016/S0008-8846(97)00031-8

3. Mehta P.K. (1994): Concrete technology at the crossroads problems and opportunities. ACI-Symposium Publication, 144, 1-30.

4. Mokarem D. W. (2002). Development of Concrete Shrinkage Performance Specifications. Virginia Polytechnic Institute and State University (Blacksburg).

5. Gribniak V., Kaklauskas G., Torres L., Daniunas A., Timinskas E., Gudonis E. (2013): Comparative analysis of deformations and tension-stiffening in concrete beams reinforced with GFRP or steel bars and fibers. Composites Part B: Engineering, 50, 158-170. doi: 10.1016/j.compositesb.2013.02.003

6. Neville A., Aïtcin, PC. (1998): High performance concrete. Materials and Structures, 31, 111-117. doi: 10.1007/ BF02486473 
7. De Larrard F., Sedran T. (1994): Optimization of UltraHigh-Performance Concrete by the Use of a Packing Model. Cement and Concrete Research, 24, 997-1009. doi: 10.1016/0008-8846(94)90022-1

8. Messan A., Ienny P., Nectoux D. (2011): Free and restrained early-age shrinkage of mortar: Influence of glass fiber, cellulose ether and EVA (ethylene-vinyl acetate). Cement and Concrete Composites, 33, 402-410. doi: 10.1016/j. cemconcomp.2010.10.019

9. Banthia N., Gupta R. (2006): Influence of polypropylene fiber geometry on plastic shrinkage cracking in concrete. Cement and Concrete Research, 36(7), 1263-1267. doi: 10.1016/j.cemconres.2006.01.010

10. Filho R. D. T., Sanjuán M. A. (1999): Effect of low modulus sisal and polypropylene fibre on the free and restrained shrinkage of mortars at early age. Cement and Concrete Research, 29, 1597-1604. doi: 10.1016/S00088846(99)00136-2

11. Passuello A., Moriconi G., Shah S. P. (2009): Cracking behavior of concrete with shrinkage reducing admixtures and PVA fibers. Cement and Concrete Composites, 31 , 699-704. doi: 10.1016/j.cemconcomp.2009.08.004

12. Pelisser F., Neto S., La Rovere H. L., Pinto R. C. (2010): Effect of the addition of synthetic fibers to concrete thin slabs on plastic shrinkage cracking. Construction and Building Materials, 24, 2171-2176. doi: 10.1016/j.conbuildmat. 2010.04.04

13. Soltani M., Xuehui A., Koichi M. (2003): Cracking response and local stress characteristics of RC membrane elements reinforced with welded wire mesh. Cement and Concrete Composites, 26, 389-404. doi: 10.1016/S09589465(03)00035-0

14. Saje D., Bandelj B., Šušterščik J. (2010): Shrinkage of Polypropylene Fiber-Reinforced High-Performance Concrete. Journal of Materials in Civil Engineering, 23(7), 941-952.

15. Boghossian E., Wegner L. D. (2008): Use of flax fibres to reduce plastic shrinkage cracking in concrete. Cement and Concrete Composites, 30, 929-937. doi: 10.1016/j. cemconcomp.2008.09.003

16. Sivakuram A., Santhanam M. (2007): A quantitive study on the plastic shrinkage cracking in high strength hybrid fibre reinforced concrete. Cement and Concrete Composites, 29(7), 575-581. doi: 10.1016/j.cemconcomp.2007.03.005

17. Tongaroonsri S., Tangtermsirikul S. (2008): Effect of mineral admixtures and curing periods on shrinkage and cracking age under restrained condition. Construction and Building Materials, 23(2), 1050-1056. doi: 10.1016/j. conbuildmat.2008.05.023

18. Kambiz R., Schlitter J., Bentz D., Weiss J. (2011): Parametric Assessment of Stress Development and Cracking in Internally Cured Restrained Mortars Experiencing Autogenous Deformations and Thermal Loading. Advances in Civil Engineering, 2011, 870128. doi: 10.1155/2011/870128

19. Meddah M. S., Suzuki M., Sato R. (2011): Influence of a combination of expansive and shrinkage-reducing admixture on autogenous deformation and self-stress of silica fume high-performance concrete. Construction and Building Materials, 25(1), 239-250. doi: 10.1016/j. conbuildmat.2010.06.033

20. Corinaldesi V. (2012): Combined effect of expansive, shrinkage reducing and hydrophobic admixtures for durable self- compacting concrete. Construction and Building Materials, 36, 758-764. doi: 10.1016/j.conbuildmat.2012.04.129

21. Oliveira J. M., Ribeiro A. B., White F. G. (2014): Combined effect of expansive and shrinkage reducing admixtures to control autogenous shrinkage in self-compacting concrete. Construction and Building Materials, 52, 267-275. doi: 10.1016/j.conbuildmat.2013.11.033

22. Dransfield J. (2003). Admixtures for concrete, mortar and grout. In: Advanced Concrete Technology, pp. 3-36.

23. Maia L., Figueiras F., Nunes S., Azenha M., Figueiras F. (2012): Influence of shrinkage reducing admixtures on distinct SCC mix compositions. Construction and Building Materials, 35, 304-312. doi: 10.1016/j.conbuildmat.2012. 02.033

24. Gettu R., Roncero, J., Martin M. A. (2002): Study of the Behavior of Concrete with Shrinkage Reducing Admixtures Subjected to Long-Term Drying. ACI - Symposium Publication, 206, 157-166.

25. LST EN 12390-2:2019 (2019). Testing hardened concrete - Part 2: Making and curing specimens for strength tests.

26. LST EN 12390-7:2019 (2019). Testing hardened concrete - Part 7: Density of hardened concrete.

27. LST EN 12390-3:2019 (2019). Testing hardened concrete - Part 3: Compressive strength of test specimens.

28. LST EN 12390-5:2019 (2019). Testing hardened concrete - Part 5: flexure strength of test specimens.

29. LST EN 12390-16:2019 (2019). Testing hardened concrete - Part 16: Determination of concrete shrinkage.

30. Janotka I. (2001): Hydration of the cement paste with $\mathrm{Na}_{2} \mathrm{CO}_{3}$ addition. Ceramics - Silikáty, 45 (1) 16-23.

31. Wang Y., He F., Wang J., Hu Q. (2019): Comparison of effects of sodium bicarbonate and sodium carbonate on the hydration and properties of Portland cement paste. Materials, 12, 1-22. doi: 10.3390/ma12071033

32. Nicoleau L., Nonat A., Perrey D. (2013): The di- and tricalcium silicate dissolutions. Cement Concrete Research, 47, 14-30. doi: 10.1016/j.cemconres.2013.01.017

33. Nicoleau L., Nonat A. (2016): A new view on the kinetics of tricalcium silicate hydration. Cement and Concrete Research, 86, 1-11. doi: 10.1016/j.cemconres.2016.04.009

34. Wang Y., He F., Wang J., Wang C., Xiong Z. (2019): Effects of calcium bicarbonate on the properties of ordinary Portland cement paste. Construction and Building Materials, 225, 591-600. doi: 10.1016/j.conbuildmat.2019.07.262

35. Han J., Wang K., Shi J., Wang Y. (2014): Influence of sodium aluminate on cement hydration and concrete properties. Construction and Building Materials, 64, 342-349. doi: 10.1016/j.conbuildmat.2014.04.089

36. Jang J. G., Kim H. J., Park S. M., Lee H. K. (2015): The influence of sodium hydrogen carbonate on the hydration of cement. Construction and Building Materials, 94,746-749. doi: 10.1016/j.conbuildmat.2015.07.121

37. Reddy V.V., Rao H.S., Jayaveera K.N. (2006): Influence of strong alkaline substances (sodium carbonate and sodium bicarbonate) in mixing water on strength and setting properties of concrete. Indian Journal of Engineering and Materials Sciences, 13, 123-128.

38. Reddy L.V.G., Krishna B. (2014): Influence of $\mathrm{Na}_{2} \mathrm{CO}_{3}$, $\mathrm{NaHCO}_{3}$ and Organic Substances (Algae) in Water on Physical Properties of Blended Pozzolonic Portland Cement. International Journal of Engineering Research and Technology, 3, 35-41. 